\title{
Hybrid Control of Interconnected Diesel-generators for Marine Power Station
}

\author{
Guichen Zhang \\ State Laboratory of Ocean Engineering \\ Shanghai Jiao Tong University \\ Shanghai, China
}

\author{
Jiqing He \\ Dept. of Naval Architecture and Marine Engineering \\ University of Strathclyde \\ Glasgow, UK
}

\begin{abstract}
The conventional control strategy of speed regulator in marine power paralleling system is respective control for interconnected diesel-generators. Taking into account the influence of the ship power paralleling system, a hybrid control model is presented in this paper. It is proved that both speed control and power regulation of the individual diesel-generator becomes possible. To this end, a novel control strategy is developed for the design of suitable model free adaptive (MFA) controller. Using the proposed model and the new control strategy, the application of speed-power coupled control and its effectiveness are extensively studied. The method is tested on COSCO (China Ocean Shipping (Group) Company) ship power system, which is mostly used as a teaching and training system for marine electrical engineers.
\end{abstract}

Keywords- Marine power station, Speed-power regulation, Hybrid control, MFA

\section{INTRODUCTION}

Electrical power systems play an important role in oceangoing ships. This system usually consists of many dieselgenerators and many kinds of loads while their total power demands vary continuously throughout the ship. As we all know, the ship power capacity of an individual dieselgenerator is relatively low, two or more diesel-generators are necessary to run in parallel. The actual power output required from each of the interconnected diesel-generator in accordance with load changes is dealt with by speed regulators in order to keep system frequency at the scheduled value, and maintain appropriated power contributions of each interconnected diesel-generators.

The speed-power control of an interconnected power system is important in electrical power system design and operation, it is indispensable for keeping the power system frequency and interchange of power output at the specified values, Based on this idea, many control strategies have been proposed [1,2]. The marine diesel-generator's speedfrequency control system based on sliding mode control (SMC) scheme is introduced in [3], which consists of a conventional governor based on a standard speed error signal and an auxiliary loop incorporating current signal as a feedforward control. [4] presents hybrid controller (HC) combining with Siemens-Schottel-Propulsion (SSP) speed, torque and power. [5] and [6] analyze the dynamic characteristics of the diesel engine speed regulation system, build a nonlinear mathematical model and design a nonlinear $\mathrm{H}$-two/H-infinity controller.
In order to meet the new control requirements, new control techniques are used in the system successfully. This paper presents a novel methodology for the design of coupling control for interconnected diesel-generators. MFA (model free adaptive) has been already applied on marine power system [7], it is capable of providing good and consistent power control performance, despite wide variations in the system operating conditions. The application of speed-power coupled control and its effectiveness is tested on COSCO (China Ocean Shipping (Group) Company) ship power system.

\section{Design Of Hybrid CONTROL System For DiesEL- GENERATOR}

In order to develop the model relevant for hybrid control strategies under the conditions discussed previously, principle diagram of interconnected diesel-generators system is shown in Fig.1, it consists of diesel engines, synchronous generators, MFA controller, fuel actuators, air control breakers (ACB) and common bus bar.

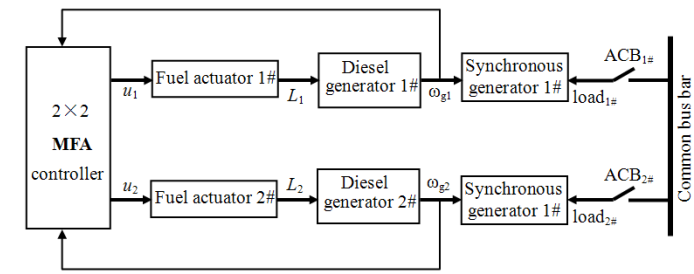

Figure 1. Principle diagram of interconnected diesel-generators

Fuel actuator proportionally converts the governor output control signals into the shaft displacement outputs. Diesel engine torque-speed characteristic is a family of smooth curves, which can be used to approximate a number of linear segments $[5,6]$. Assume that all individual diesel-generator power outputs are equivalent, the governor outputs control signal in accordance with the speed-droop characteristics of each engine. The diesel engine speed determines the frequency of the ship electrical output while the diesel engine power determined by the ship electrical power load.

\section{CONTRol Model Of Diesel-Generator}

Marine synchronous generators used to convert mechanical power to ac electric power. This paper explores the operation of synchronous generators, when operating together with other generators. It is very important to establish marine synchronous generator model for ship 
power system analysis. The synchronous generator model has been established in $[8,9]$, while operating alone. In order to develop marine synchronous generators model for a hybrid control of interconnected diesel-generators, the synchronous generators model is shown in Figure. 2

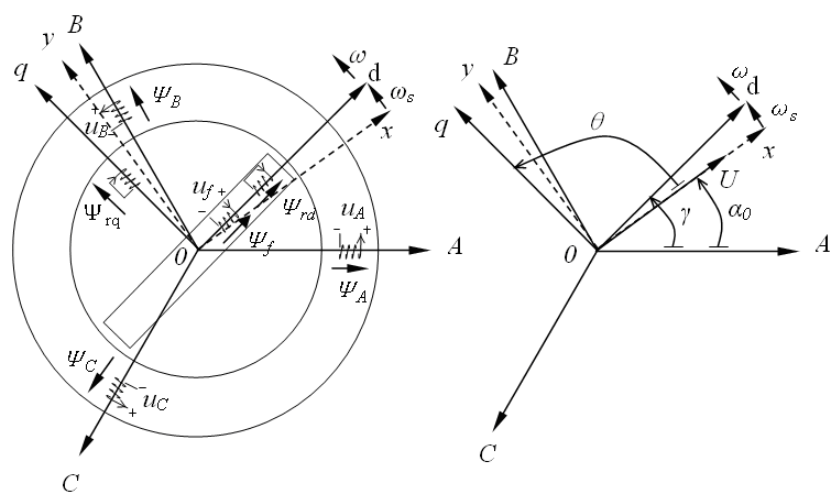

Figure 2. Structure diagrams for dual-polar generator and position of axis

Where $\left(\Psi_{\mathrm{A}}, \Psi_{\mathrm{B}}\right.$ and $\left.\Psi_{\mathrm{C}}\right)$ and $\left(i_{\mathrm{A}}, i_{\mathrm{B}}\right.$ and $\left.i_{\mathrm{C}}\right)$ are flux linkage and phase current of stator three-phase (A, B and $\mathrm{C}$ ) winding, respectively. $x-y$ is the synchronous rotation axes. $d$-axis is the centerline of the rotor field windings, $q$-axis leads $d$-axis $90^{\circ}$ electrical angle alone rotor rotation direction. Exciting winding $f$ is in $d$-axis; the equivalent damping windings $r_{d}$ and $\mathrm{r}_{\mathrm{q}}$ belong to $d$-axis and $q$-axis, respectively. $\omega$ is the angular velocity of rotor rotation, $\omega_{\mathrm{g}}$ is synchronous angular velocity.

Because the ship power system is the three-phase insulation system, zero-sequence component equal to zero. The transformation equations is marine synchronous generator is as follows:

$$
\left\{\begin{array}{l}
\frac{d \Psi_{d}}{d t}+\Psi_{q} \frac{d \gamma}{d t}-R I_{d}=U_{d}=-U_{s d} \\
-\frac{d \Psi_{q}}{d t}+\Psi_{d} \frac{d \gamma}{d t}-R I_{q}=U_{q}=-U_{s q} \\
\frac{d \Psi_{f}}{d t}+R_{f} I_{f}=U_{f} \\
\frac{d \Psi_{r d}}{d t}+R_{r d} I_{r d}=0 \\
\frac{d \Psi_{r q}}{d t}+R_{r q} I_{r q}=0 \\
J \frac{d^{2} \gamma}{d t^{2}}+\frac{3}{2}\left(\Psi_{d} I_{q}+\Psi_{q} I_{d}\right)=M_{M}
\end{array}\right.
$$

For convenience, this paper utilizes $x_{\text {ad }}$ basic value system, per-unit value equations of marine synchronous generator can rewrite Eq. (1) as follows:

$$
\left\{\begin{array}{l}
p \psi_{d}+\psi_{q} p \gamma-r i_{d}=u_{d}=-u_{s d} \\
-p \psi_{q}+\psi_{d} p \gamma-r i_{q}=u_{q}=-u_{s q} \\
T_{d 0} p \psi_{f}+i_{f}=T_{d 0} p \psi_{f}+e_{a f}=u_{f} \\
T_{r d} p \psi_{r d}+i_{r d}=T_{r d} p \psi_{r d}+e_{r d}=0 \\
T_{r q} p \psi_{r q}+i_{r q}=T_{r q} p \psi_{r q}+e_{r q}=0 \\
T_{J} p^{2} \gamma=M_{M}{ }^{*}-M^{*}=M_{M}{ }^{*}-\left(\psi_{d} i_{q}+\psi_{q} i_{d}\right)
\end{array}\right.
$$

After adopting per-unit value method, marine synchronous generator flue linkage equations can obtain as follows:

$$
\left\{\begin{array}{l}
\psi_{d}=e_{a f}-x_{d} i_{d}+e_{r d} \\
\psi_{q}=x_{q} i_{q}+e_{r q} \\
\psi_{f}=e_{a f}-\frac{x_{a d}^{2}}{x_{f}} i_{d}+\frac{x_{a d}}{x_{f}} e_{r d} \\
\psi_{r d}=e_{r d}-\frac{x_{a d}^{2}}{x_{r d}} i_{d}+\frac{x_{a d}}{x_{r d}} e_{a f} \\
\psi_{r q}=e_{r q}+\frac{x_{a q}^{2}}{x_{r q}} i_{q}
\end{array}\right.
$$

Substituting Eq.(3) in Eq.(2), obtained as follows:

$$
\left\{\begin{array}{l}
p\left(e_{a f}-x_{d} i_{d}+e_{r d}\right)+\left(x_{q} i_{q}+e_{r q}\right) p \gamma-r i_{d}=u_{d} \\
\left(e_{a f}-x_{d} i_{d}+e_{r d}\right) p \gamma-p\left(x_{q} i_{q}+e_{r q}\right)-r i_{q}=u_{q} \\
e_{a f}+T_{d 0} p\left(e_{a f}-\frac{x_{a d}^{2}}{x_{f}} i_{d}+\frac{x_{a d}}{x_{f}} e_{r d}\right)=u_{f} \\
e_{r d}+T_{r d} p\left(e_{r d}-\frac{x_{a d}^{2}}{x_{r d}} i_{d}+\frac{x_{a d}}{x_{r d}} e_{a f}\right)=0 \\
e_{r q}+T_{r q} p\left(e_{r q}+\frac{x_{a q}^{2}}{x_{r q}} i_{q}\right)=0 \\
T_{J} p^{2} \gamma+\left[\left(e_{a f}-x_{d} i_{d}+e_{r d}\right) i_{q}+\left(x_{q} i_{q}+e_{r q}\right) i_{d}\right]=M_{M}
\end{array}\right.
$$

Where $i$ and $e$ are the per-units of marine synchronous generator.

Damping ratios are as follows:

$$
\begin{aligned}
& \rho_{d}=\frac{r}{x_{d}} ; \\
& \rho_{q}=\frac{r}{x_{q}} ; \\
& \rho_{f}=\frac{r_{f}}{x_{f}} ;
\end{aligned}
$$




$$
\begin{gathered}
\rho_{r d}=\frac{r_{r d}}{x_{r d}} ; \\
\rho_{r q}=\frac{r_{r q}}{x_{r q}}
\end{gathered}
$$

Coupling coefficients are as follows:

$$
\begin{aligned}
& \mu_{d}=\frac{x_{a d}^{2}}{x_{f} x_{d}}=\frac{x_{d}-x_{d}^{\prime}}{x_{d}}=1-\frac{x_{d}^{\prime}}{x_{d}}=1-\sigma_{d} ; \\
& \mu_{d}^{\prime}=\frac{x_{a d}^{2}}{x_{r d} x_{d}}=\frac{x_{d}-x_{d}^{\prime \prime}}{x_{d}} ; \\
& \mu_{q}=\frac{x_{a q}^{2}}{x_{r q} x_{q}}=\frac{x_{q}-x_{q}^{\prime \prime}}{x_{q}} ; \\
& \mu_{a}=\frac{x_{a d}^{2}}{x_{f} x_{r d}}=g_{1} g_{2} ; \\
& g_{1}=\frac{x_{a d}}{x_{f}}=\sqrt{\frac{\mu_{d} \mu_{a}}{\mu_{d}^{\prime}}} ; g_{2}=\frac{x_{a d}}{x_{r d}}=\sqrt{\frac{\mu_{d}^{\prime} \mu_{a}}{\mu_{d}}}
\end{aligned}
$$

Where $\mu_{d}, \mu_{d}^{\prime}, \mu_{q}$ and $\mu_{a}$ are mutual inductance coefficients of stator three-phase and excitation circuit, stator three-phase and vertical axis damping circuit, stator threephase and abscissa axis damping circuit, excitation circuit and vertical axis damping circuit, respectively. $\sigma_{d}$ is leakage coefficient of stator three-phase and excitation circuit, $x_{d}$ and $x_{q}$ are the vertical and horizontal axis reactance, respectively; $x_{d}^{\prime}$ is the vertical axis transient reactance; $x_{d}^{\prime \prime}$ and $x_{q}^{\prime \prime}$ are the vertical and horizontal axis subtransient reactance, respectively.

Revolution slip is as follows:

$$
s=\frac{\omega-\omega_{s}}{\omega_{s}}
$$

Assume that vector voltage and synchronous rotation axis is coincidence, as follows:

$$
\gamma=\theta-\frac{\pi}{2}+\alpha_{0}+\omega_{s} t
$$

From Eq.(5) and (6) one can arrive at

$$
\left\{\begin{array}{l}
s=\frac{\omega-\omega_{s}}{\omega_{s}}=\frac{\frac{d \theta}{d t}}{\omega_{s}}=p \theta \\
p \gamma=\frac{\frac{d \gamma}{d t}}{\omega_{s}}=\frac{\frac{d \theta}{d t}+\omega_{s}}{\omega_{s}}=p \theta+1=s+1
\end{array}\right.
$$

Therefore, substituting damping ratio $\rho$, coupling coefficient $\mu$ and Eq,(7) in Eq.(4) we obtain

$$
\left\{\begin{array}{l}
-\left(\rho_{d}+p\right) x_{d} i_{d}+p\left(e_{a f}+e_{r d}\right)+(1+s) x_{q} i_{q}+(1+s) e_{r q}=u_{d} \\
-\left(\rho_{q}+p\right) x_{q} i_{q}-p e_{r q}-(1+s) x_{d} i_{d}+(1+s)\left(e_{a f}+e_{r d}\right)=u_{q} \\
-\mu_{d} p x_{d} i_{d}+\left(\rho_{f}+p\right) e_{a f}+g_{1} p e_{r d}=\rho_{f} \mu_{f} \\
-\mu_{d}^{\prime} p x_{d} i_{d}+\left(\rho_{r d}+p\right) e_{r d}+g_{2} p e_{a f}=0 \\
\mu_{q} p x_{q} i_{q}+\left(\rho_{r q}+p\right) e_{r q}=0 \\
p \theta-s=0 \\
T_{J} p s+\left[\left(e_{a f}-x_{d} i_{d}+e_{r d}\right) i_{q}+\left(x_{q} i_{q}+e_{r q}\right) i_{d}\right]=M_{M}
\end{array}\right.
$$

$e_{r d}=e_{r q}=0$ expresses undamped circuit condition, Eq.(8) can be simplified as follows:

$$
\left\{\begin{array}{l}
-\left(\rho_{d}+p\right) x_{d} i_{d}+p e_{a f}+(1+s) x_{q} i_{q}=u_{d} \\
-\left(\rho_{q}+p\right) x_{q} i_{q}-(1+s) x_{d} i_{d}+(1+s) e_{a f}=u_{q} \\
-\left(x_{d}-x_{d}^{\prime}\right) p i_{d}+\left(\rho_{f}+p\right) e_{a f}=\rho_{f} \mu_{f} \\
p \theta-s=0 \\
T_{J} p s+e_{q} i_{q}=M_{M}
\end{array}\right.
$$

Actuator differential equation [5] is expressed as follows:

$$
\frac{\mathrm{d} L}{\mathrm{~d} t}=-\frac{L}{T}+\frac{K}{T} u
$$

Where $L$ is the displacement of actuator output shaft, $u$ is the control signal of the speed regulator; $T$ and $K$ are the time constant and gain of the actuator, respectively.

The dynamic equation of the diesel-generator [6] is:

$$
J \frac{\mathrm{d} \omega_{\mathrm{g}}}{\mathrm{d} t}+\xi p \omega_{\mathrm{g}}=Q_{1}-Q_{2}
$$

Where $\boldsymbol{J}, \omega_{\mathrm{g}}$ and $\xi$ are the moment of inertia, the rotation speed and the damping coefficient of the diesel-generator, respectively. $p$ is the generator pole pairs, $Q_{1}$ is the diesel engine output torque, $Q_{2}$ is the generator resistance torque.

Marine synchronous generator model [8] equation is as follows:

$$
J \ddot{\delta}+\xi \ddot{\delta}=P_{1}-P_{2}
$$

Where $\delta$ is the generator rotor angle referred to the infinite bus, $P_{1}$ is the mechanical power supplied by the diesel engine, $P_{2}$ is the electrical power.

Since engine torque-speed characteristic can be used to approximate linear segments, the hybrid control model of the speed regulating system can be approximated as the convolution of linear part, integral part and first-order inertial part, its transfer function is as follows:

$$
G(s)=\left(K_{1} s+b\right) * \frac{1}{T_{1} s} * \frac{K_{2} e^{-\tau s}}{1+T_{2} S}
$$

Where $K_{1}$ and $b$ are the slope and intercept of the segment corresponding to the rated speed, $T_{1}$ is the integral 
constant, $K_{2}, T_{2}$ and $\tau$ are the gain, inertia and delay time of the hybrid control model, respectively.

MFA controller based on neural network technology including decoupling control technology is used to combine control of the individual speed regulator of each paralleling engine, to overcome adverse effects of superimposing or offsetting control action between interconnected dieselgenerators.

\section{Simulation Results}

In this paper, the main parameters of diesel engine speed control system are as follows:

Diesel-generator rated power $P=50 \mathrm{kw}$, maximum power $P_{\max }=62 \mathrm{kw}$; rated speed $n=1800 \mathrm{rpm}$, diesel-generator moment of inertia $\boldsymbol{J}=2.873 \mathrm{~kg} \cdot \mathrm{m}^{2}$, diesel-generator damping coefficient $\xi=0.23$, generator pole pairs $p=2$, engine rated torque $Q=47.6 \mathrm{Nm}$, the maximum output shaft travel of fuel actuator $L_{\max }=8 \mathrm{~mm}$.

The parameters of the hybrid control model are as follows:

$K_{11}=1, K_{12}=1 ; K_{21}=1, K_{22}=1 ; T_{11}=1.5 \mathrm{~s}, T_{12}=1.5 \mathrm{~s} ; T_{21}=3 \mathrm{~s}$, $T_{22}=5 \mathrm{~s} ; \quad \tau_{1}=3 \mathrm{~s}, \quad \tau_{2}=5 \mathrm{~s} ; \quad b_{1}=0.6, \quad b_{2}=0.65$; sample interval $T_{\mathrm{s}}=0.1 \mathrm{~s} . \quad K_{1 i}, \quad K_{2 i}, \quad T_{1 i}, \quad T_{2 i}, \quad \tau_{i}$ and $b_{i}$ are parameters corresponding to $K_{1}, K_{2}, T_{1}, T_{2}, \tau$ and $b$, where $i=1$ and $i=2$ represent $1 \#$ and $2 \#$ diesel-generators, respectively. The amplitude of load disturbance is $10 \%$, white noise amplitude is 8 .

The No.1\# and 2\# diesel-generators operate in parallel, the simulation results are as shown in Fig.3 and Fig.4. $\triangle P / P_{\max }$ and $\triangle L / L_{\max }$ are the percentage of power outputs of diesel engine and displacements of actuator output shaft, respectively.

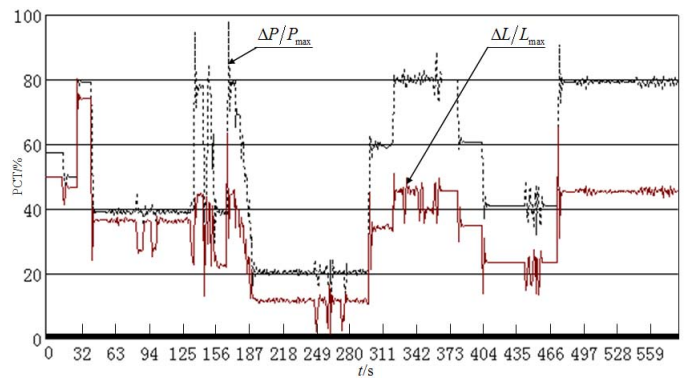

Figure 3. Simulation result of 1\# diesel-generator

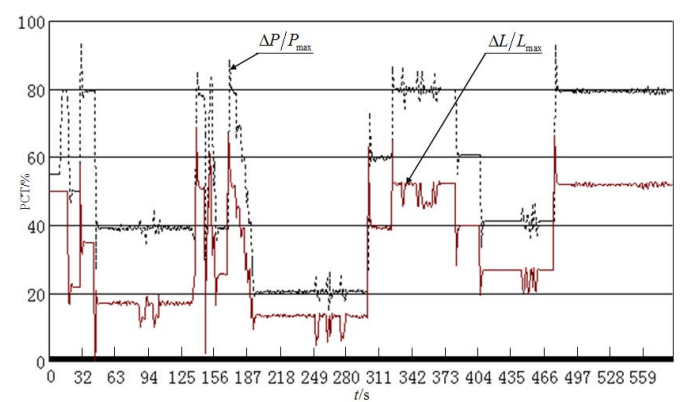

Figure 4. Simulation result of $2 \#$ diesel-generator
In Fig.3 and Fig.4, also shows the power distribution and the displacement changes of fuel oil rack between dieselgenerators in parallel. Time constant and delay time of $2 \#$ are longer than that of $1 \#$, which means $T_{22}>T_{21}$ and $\tau_{2}>\tau_{1}$. The $\triangle P$ and $\triangle L$ curves of $2 \#$ also oscillate intensely than that of $1 \#$ under transient disturbance, the $1 \#$ and $2 \#$ power distributions are equally shared in steady state, but the $1 \#$ fuel oil supply is obviously different from that of $2 \#$, because of their different model parameters. When load disturbance or any changes of $1 \#$ and $2 \#$ power occurs, $1 \#$ and $2 \#$ output will synchronously change, so as to maintain interconnected system stability.

\section{SUMMARIES}

In this paper, a novel approach for the hybrid control of interconnected diesel-generators is proposed. A hybrid controller design for speed-power control of interconnected diesel-generators has been developed based on MFA technique. The performance of the hybrid controller has been verified by simulating a two interconnected diesel-generators system, to keep the frequency of the ship power system at scheduled value and to allocate the power equally to the individual diesel-generators.

\section{ACKNOWLEDGEMENTS}

This work was financially supported from China Postdoctoral Science Foundation (Grant No: 20110490716).

\section{REFERENCES}

[1] D.P.Iracleous; A.T.Alexandridis. A multi-task automatic generation control for power regulation $[\mathrm{J}]$, Electric Power Systems Research, 2005, v73, n3, PP 275-285

[2] GOSHAIDAS Ray; A.N.Prasad; G.Durga Prasad. Design of a robust load-frequency controller for interconnected power systems based on the singular-value decomposition method [J], Electric Power Systems Research, 1996, v37, n3, PP209-219

[3] ZHANG Gui-chen. Speed-frequency controller design based on sliding mode for marine diesel-generator [C], 2010 2nd WRI Global Congress on Intelligent Systems (GCIS2010), IEEE Computer Society, 2010, v2, PP31-34

[4] ZHANG Gui-chen; MA Jie. Torque-power-speed hybrid control of marine electric propulsion system [C]. 2010 International Conference on Intelligent Computation Technology and Automation (ICICTA2010), IEEE Computer Society, 2010, v3, PP1052-1056

[5] HUANG Man-lei; WANG Chang-hong. Nonlinear $\mathrm{H} \infty$ Governor for diesel engine of ship power station [J], Transactions of China Electrotechnical Society, 2006, v21, n10, PP56-61

[6] HUANG Man-lei; SONG Ke-ming; WEI Zhi-da. Nonlinear H-two/Hinfinity speed regulator for a diesel-generator set [J], Control Theory and Applications, 2009, v26, n8, PP873-878

[7] ZHANG Gui-chen. Marine power management system based on model free adaptive control [C], 2010 International Conference on Computer Application and System Modeling (ICCASM 2010), IEEE Computer Society, 2010, v15, PP15160-15163

[8] J.De Leon-Morales, K.Busawon, S.Acha-Daza. A robust observerbased controller for synchronous generators [J]. Electrical Power and Energy Systems, 2001, v23, n3, pp: 195-211

[9] J. Alvarez-Ramirez, I. Cervantes, R. Escarela-Perez and et al. A twoloop excitation control system for synchronous generators [J]. Electrical Power and Energy Systems, 2005, v27,n8, pp:556-566 